\title{
Genetic Characterization Among Carbapenem-resistant Escherichia coli Strains Using Enterobacterial Repetitive Intergenic Consensus Polymerase Chain Reaction (ERIC-PCR) Fingerprinting in South Africa
}

Kingsley Ehi Ebomah ( $\square$ 201411619@ufh.ac.za)

University of Fort Hare https://orcid.org/0000-0002-8192-0428

Anthony Ifeanyi Okoh

University of Fort Hare Faculty of Science and Agriculture

Research

Keywords: Antibiotics, carbapenem, dendrogram, Escherichia coli, Resistance genes, Virulence genes

Posted Date: August 2nd, 2020

DOI: https://doi.org/10.21203/rs.3.rs-49578/v1

License: (c) (1) This work is licensed under a Creative Commons Attribution 4.0 International License. Read Full License 


\section{Abstract}

Background Carbapenems belong to beta-lactam class of antibiotics usually considered as the last line of defense because they can be effective against severe infections caused by prevalent multidrug-resistant (MDR) pathogens. However, carbapenems can be deactivated by bacteria that produce carbapenemase (beta-lactamase). This study was conducted to screen for carbapenem-resistance genes (CRGs) harbored by pathogenic strains of Escherichia coli recovered from different environmental samples. We also assessed the genetic relatedness among selected $E$. coli pathotypes using enterobacterial repetitive intergenic consensus-polymerase chain reaction (ERIC-PCR).

Method: Molecular identification and characterization of the presumptive isolates were performed using PCR and isolates that exhibited antimicrobial resistance (AMR) phenotypically were further screened for some relevant CRGs (bla $a_{N D M-1}, b_{1} a_{K P C}$ and $\left.b / a_{O X A-48-l i k e}\right)$. Furthermore, ERIC-PCR was used to determine the similarity and diversity of $31 \mathrm{E}$. coli strains which were randomly selected from the different sources analyzed in this study.

Result Our findings revealed a total of 238 presumptive $E$. coli isolates, out of which 192 were confirmed positive for uidA gene. Further screening revealed $77(40 \%)$ isolates belong to six key E. coli pathotypes and 70 of them exhibited phenotypic AMR. Additionally, twenty-nine (41\%) of the 70 MDR pathogenic E. coli strains harbored CRGs; with 24 strains harboring bla ${ }_{N D M-1}, 8$ harboring $b / a_{K P C}$ and 2 harboring bla ${ }_{O X A-48-l i k e}$ genes.

Conclusion Findings also suggest that the selected E. coli pathotypes belonged to different genomic clusters, while the cluster analysis showed a possible genetic diversity among aquatic and farm isolates. Proper treatment of final effluents before discharge as well as the development of more effective strategies to control and manage the use of antimicrobial agents were strongly recommended.

\section{Background}

Escherichia coli consist of a variety of strains widely disseminated in different ecological units across the world ranging from natural environmental niches to the digestive tracts in animals and humans [1]. Nonetheless, $E$. coli is frequently present in the normal microbiota of the human gut thereby playing an important role in human's livelihood [2], yet it is regarded as a suitable fecal indicator for food and water contamination [3]. There are diverse strains of $E$. coli amongst which consist of highly pathogenic strains responsible for serious infections such as Urinary Tract Infections (UTI), gastroenteritis and diarrhea. The pathogenicity is determined by strains that harbor virulence genes (VGs), and among which are the main causative agents of diarrhea such as Enteropathogenic E. coli (EPEC), Enteroaggregative E. coli (EAEC) and Enterotoxigenic E. coli (ETEC) which harbor VGs comprising bfp (bundle-forming pili), Aafl (aggregative adherence fimbrae I) and It (heat-labile enterotoxin) respectively [4, 5]. Other relevant $E$. coli pathotypes and VGs they harbor include the following: diffusely adherent E. coli, DAEC (VG: daae); neonatal meningitis-causing E. coli, NMEC (VG: ibeA); enterohaemorrhagic E. coli, EHEC (VG: stx/eae); shiga toxin-producing E. coli, STEC (VG: stx1/stx2) [6]. For many years, beta-lactam class of antibiotics remained the key therapeutic option for stern infections, and carbapenems are often considered antimicrobials of last choice [7]. Antimicrobial-resistant bacteria (ARB) such as carbapenem-resistant Escherichia coli (CREC) can transfer antimicrobial resistance genes (ARGs) to other bacterial species [8]. Carbapenem-resistant Enterobacteriaceae (CRE) can acquire ARGs that produce $\beta$-lactamases (carbapenemases) encoding multiple antibiotic resistance (MAR) mechanisms which can eventually bring about the hydrolysis of other antimicrobial agents, thereby limiting treatment options $[9,10]$. Moreover, many infections triggered by these multiple drug resistant (MDR) bacterial strains are often linked with higher fatality rates than those of infections instigated by microorganisms susceptible to carbapenems $[11,12]$. ARGs such as $b / a_{N D M-1}, b_{1} a_{K P C}$ and bla ${ }_{O X A-48-l i k e}$ are the most common CRGs widely reported in pathogenic E. colistrains [13].

The dissemination of ARGs among CREC is a matter of great concern considering that hospital wastewater effluents constitute a distinct type of waste that remains extremely hazardous since they comprise a myriad of drug deposits and infectious agents and are consequently a significant source of MDR bacterial strains [14]. Wastewater treatment plants (WWTPs) are also key hotspots affiliated with the fecology of pathogens and the dissemination of emerging superbugs. These niches are considered as reservoirs of nutrients and/or abundance of elevated bacterial numbers as well as sub-toxic levels of antibiotics favorable for the survival of ARB $[15,16]$. Reports have revealed the implications of the reuse of treated wastewater final effluent for irrigation purposes in farms, likewise, a rise of soil microbial biomass as a result of wastewater irrigation was observed in many studies [17-19]. Agricultural practices involving reclaimed wastewater reuse serve as an avenue for pathogens (particularly $E$. coli) to be transferred to foods (e.g. raw vegetables and fruits), and available channels for the horizontal transfer of ARGs to other harmless bacteria [20, 21].

The knowledge of microbial diversities and understanding the role of environmental pathogens as well as the ecological relationships within species are vital to public health and epidemiological studies [22]. Due to vast variations in bacterial genes, the use of easy, rapid, effective and cheap techniques, such as molecular fingerprints and molecular diagnostic tools like ERIC-PCR may be considered as straightforward protocols for the evaluation of genetic relatedness of E. coli [23]. Among several more recent PCR-based techniques, such as Real-Time Whole-Genome Sequencing (WGS), randomly amplified polymorphic DNA (RAPD) and Multilocus Sequencing Typing (MLST), the Enterobacterial Repetitive Intergenic Consensus (ERIC) PCR is a very affordable and swift method that has conserved and repeated sequences which can be observed in microbes (including bacteria and some fungi) [24, 25]. Unlike the other aforementioned PCR-based techniques, ERIC-PCR has been especially useful as a typing method for multi-resistant Enterobacteriaceae strains and allows for a straightforward identification of genome fragments useful as genomespecific markers for dynamic monitoring of bacterial populations in complex communities (e.g. human gut microflora) [26]. In this technique, 
different strains of bacteria can be differentiated based on the amplification of random and rapid dispersal of inter-genome parts. Interestingly, bacterial strains vary in the regularity of repetitive sequences, hence, this procedure yields different arrays of specific primers which are designed to be able to fasten the recurrent sequences and to amplify the distances amid those attached primers [27]. Those incomplete palindrome sequences are frequently identified inside transcribed areas linked with intergenic consensus.

Remarkably, there is significant diversity of gene copy numbers which induces the evolution processes among specific bacterial strains within a certain species such as E. coli [28]. Different environmental niches such as surface waters are exposed to discharges from various sources, in receipt of microbial contaminants that originate from both agricultural and domestic origins, hence, there is a need for more studies investigating CRE isolates recovered from different samples in the environment of South Africa [29]. The aim of this present study was to investigate the antimicrobial resistance profiles and pathovars distribution of Escherichia coli recovered from some environmental niches in three District Municipalities (DMs) within the Eastern Cape Province (ECP), South Africa as well as to determine the genetic relatedness of selected E. coli strains using ERIC-PCR.

\section{Method}

\section{Sample collection}

A total of 243 different environmental samples ranging from surface water (47), WWTPs final effluents (29), hospital effluents (27) to irrigation water (45), soil (60) and vegetables (35) were collected from January to September 2018. Water samples (1.5L) was collected in duplicate using sterile glass bottles and transported in an ice box to the research laboratory for bacteriological analyses within 6 hours of sampling. Soil samples (20 g), irrigation water (1L) and vegetable samples (5-10 g) comprising spinach, broccoli and cabbage were collected randomly from selected farms in the study areas.

Processing of the collected water samples

Membrane filter technique was adopted for the isolation of the enteric bacteria from the water samples [30]. Briefly, one hundred millilitres of the water samples were filtered using a sterile membrane filter papers of $0.45-\mu \mathrm{m}$ pore size. Afterwards, the filters were aseptically picked with sterilized forceps and carefully placed on plates of $E$. coli-coliforms chromogenic medium agar (Chromogenic media, Merck), then incubated at $37^{\circ} \mathrm{C}$ for $18-$ $24 \mathrm{~h}$. Subsequently, presumptive $E$. coli isolates were streaked onto nutrient agar (NA) plates and incubated at $37^{\circ} \mathrm{C}$ for $24 \mathrm{~h}$. Afterwards, $25^{\circ}$ glycerol stock was prepared from the cultured nutrient broths and stored at $-80^{\circ} \mathrm{C}$ for further analyses.

Processing of the collected vegetable samples

For the processing of vegetable samples, the method of Du Plessis et al. [31] was adopted. Briefly, $10 \mathrm{~g}$ of each vegetable samples was placed in a Stomacher Bag and then $90 \mathrm{~mL}$ of sterile Trypticasein Soy Broth (TSB) was introduced and macerated with Mixer machine. Thereafter, the broth was incubated for $18-24 \mathrm{~h}$ at $37^{\circ} \mathrm{C}$ in sterilized bottles. Subsequently, a loopfull of TSB was streaked on the surface of $E$. coli-coliforms chromogenic media plates and then incubated at $37^{\circ} \mathrm{C}$ for $24 \mathrm{~h}$. Single colonies from the overnight culture were streaked on NA plates, incubated at $37^{\circ} \mathrm{C}$ for $24 \mathrm{~h}$ and stored in glycerol stock for further analysis.

Processing of soil samples

We adopted the method of Da Silva et al. [32] for biological analysis of the soil samples. Sixty agricultural soil samples were randomly collected from some farms in the study area. Briefly, a total $10 \mathrm{~g}$ of each soil sample was introduced into about $90 \mathrm{~mL}$ of sterile TSB and afterwards incubated for $18-24 \mathrm{~h}$ at $37^{\circ} \mathrm{C}$. Thereafter, a loopfull of TSB was streaked on E. coli-coliforms chromogenic medium agar petri dishes and incubated at $37^{\circ} \mathrm{C}$ for $24 \mathrm{~h}$. Purification process was carried out on NA plates and incubated at $37^{\circ} \mathrm{C}$ for $24 \mathrm{~h}$. Afterwards, $25 \%$ glycerol stock was prepared from cultured nutrient broths and then stored at $-80^{\circ} \mathrm{C}$ for further analyses.

\section{Bacterial DNA extraction}

Extraction of Escherichia coli DNA was achieved using the boiling technique as previously described by Jackson et al. [33]. In brief, 4 mL of nutrient broth (NB) was prepared, presumptive isolates were resuscitated by inoculating a loopfull of each isolate into the NB. After the incubation period of about $18-24$ hours at $37^{\circ} \mathrm{C}, 1 \mathrm{~mL}$ of the broth cultures was centrifuged at $12,800 \mathrm{rpm}$ for $5 \mathrm{~min}$, the supernatants discarded and the cells were suspended in $400 \mu \mathrm{L}$ of sterile distilled water using sterile $1.5 \mathrm{~mL}$ Eppendorf tubes. The suspensions were boiled at $100{ }^{\circ} \mathrm{C}$ for 10 min in a heating block, allowed to cool and after which the suspensions were centrifuged at 12,800 rpm for 5 min and 3 microliters of supernatants per reaction were use as PCR templates.

\section{Molecular identification of E. coli}

Molecular identification of $E$. coli was carried out by PCR technique using the primer sets (F: CGC GTA CTA TAC GCC ATG AAC GTA; R: ACC GTT GAT CAC TTC GGT CAGG) and PCR conditions listed in Table S1 with some modifications in accordance with the protocols as reported elsewhere, [34] targeting uidA gene which encodes beta-Glucuronidase at $147 \mathrm{bp}$ for the molecular confirmation of E. coli. The positive control (ATCC 25922) was used. The positively confirmed $E$. coli isolates were further screened for the presence of virulence genes representing the various pathotypes using 
the primer sets reported by Ebomah et al. [6] as shown in Table S1. Verification of the PCR amplified products was determined by resolving them in $1.5 \%$ agarose gel at 135 volts for $30 \mathrm{~min}$, identified under a short-wavelength UV light source (Alliance 4.7).

\section{Antimicrobial Susceptibility test of the confirmed E. coli pathogenic strains}

All confirmed E. coli pathotypes were subjected to antimicrobial susceptibility test (AST) against 4 panels of carbapenem following Kirby-Bauer disk diffusion procedure according to the Clinical and Laboratory Standards Institute (CLSI) guidelines and results were thereby interpreted according to the CLSI [35] recommendations. The class of carbapenem antimicrobial agents includes doripenem (10 $\mu \mathrm{g})$, imipenem (10 $\mu \mathrm{g}), \mathrm{meropenem}(10 \mu \mathrm{g})$ and ertapenem $(10 \mu \mathrm{g})$. Briefly, about 100-200 mL of the bacterial overnight broth was transferred into $5 \mathrm{~mL}$ normal saline solution, which was adjusted matching 0.5 McFarland standard. Thereafter $100 \mu \mathrm{L}$ was spread on Muller-Hinton agar (MHA, Merck) plates through the use of sterilized glass spreader, and MHA plates were impregnated with $10 \mu \mathrm{g}$ of the aforementioned carbapenem antimicrobials discs (Thermofisher), incubated aerobically for $24 \mathrm{~h}$ at $37^{\circ} \mathrm{C}$. After which diameters of the zone of inhibition were measured using a ruler then interpreted according to the recommended criteria by the CLSI [35].

\section{Molecular characterization of the relevant carbapenem resistance genes}

All strains of E. coli pathotypes that exhibited phenotypic resistance against one or more of the 4 test carbapenems were further screened for the relevant carbapenem-resistance genes using PCR technique and PCR products were observed via agarose (Separation, SA) gel electrophoresis (AGE). The list of primers that were employed for the PCR are listed in Table S1 [36].

\section{ERIC-PCR and DNA amplification of E. coli strains}

From the confirmed $E$. coli strains that harbored virulence genes, 31 strains were arbitrarily selected from different sources and were subjected to PCR using the ERIC primer sets listed in Table S1. The PCR reactions were verified by resolving them in $3 \%$ agarose gel in a $1 \times$ TBE buffer (Merck), stained with ethidium bromide at 90 volts for 240 min and viewed as previously stated [37].

\section{Dendrogram and clustering analysis}

The pattern of bands in agarose gel electrophoresis regarding ERIC-PCR products was used as the principle structure for calculation of the dendrogram. The GelJ v.2.0 is a user-friendly software with computer-assisted pattern which can be used for dendrograms via gel electrophoresis images as supported by Heras et al. [37]. The dendrogram was designed to unweighted pair group method with arithmetic mean (UPGMA) which is categorized in clustering methodologies, and is based on clustering analysis.

\section{Reproducibility}

The ERIC-PCR analysis of the result can be directly correlated within a single PCR technique. In order to determine the reproducibility of this experiment, the clustered result of the 31 E. coli strains was repeated twice in further ERIC-PCR procedure.

\section{Statistical analysis}

Statistical analyses were carried out, charts and dendrograms were drawn using GelJ v.2.0 software [37]

\section{Results}

\section{Molecular Identification and pathotyping of the obtained E. coli isolates}

A total amount of 238 presumptive $E$. coli isolates was recovered from the different sample types (243 environmental samples in total). Results showed that 192 (81\%) out of the 238 isolates were positive for uidA gene. The confirmed $E$. coli isolates were then screened for the selected VGs by PCR and categorized into various pathotypes utilizing particular primers as shown in Supplementary Table (Table S1). Out of 192 confirmed E. coli isolates, a total of 77 (40\%) strains belonging to six pathotypes were identified (IbeA/NMEC 25, 13\%; eagg/EAEC 15, 8\%; daae/DAEC 11, 6\%; bfp/EPEC 6, 3\%; It/ETEC 6, 3\%; stx1/STEC 14, 7\%). However, stx2 was not detected and this could result in the low detection in STEC. Table 1 summarizes the total number of confirmed $E$. coli isolates obtained from the different sample types that were selected for the purpose of this present study. Supplementary Figure (S1) is a representation of an electrophoretic image of the amplification of uidA gene for confirmed $E$. coli isolates and Supplementary Figure (S2) represents the agarose gel electrophoresis (AGE) of the PCR products of NMEC (neonatal meningitis-causing E. coli) which harbors the VG ibeA. Based on the diverse sources, some of the E. coli strains were selected and used for the ERIC-PCR analysis to determine the similarity and diversity with regards to the different sample types. Majority of these strains (8: 25.81\%) harbored stx1 (STEC) which were isolated from mainly farm soil samples, and the remaining harbored $b f p$ (EPEC) isolated from river water samples, final effluent, hospital effluent and irrigation water. 
Table 1

Total number of confirmed E. coli pathotypes obtained from different sample types in 3 District Municipalities.

\begin{tabular}{|lllllll|}
\hline S/N Sample types & \multicolumn{5}{l|}{ Number of confirmed E. coli pathotypes (cfu / ml) } \\
\cline { 2 - 6 } & IbeA/NMEC & Aafl/EAEC & daae/DAEC & bfp/EPEC & It/ETEC & stx1/STEC
\end{tabular}

\begin{tabular}{|llllllll|}
\hline 1 & Hospital effluent & 5 & 4 & 1 & 1 & 3 & 1 \\
\hline 2 & WWTP final effluent & 8 & 6 & 7 & 0 & 2 & 1 \\
\hline 3 & Surface water & 8 & 2 & 2 & 4 & 1 & 4 \\
\hline 4 & Irrigation water & 2 & 2 & 1 & 0 & 0 & 1 \\
\hline 5 & Farm soil & 0 & 1 & 0 & 1 & 0 & 3 \\
\hline 6 & Vegetables & 2 & 0 & 0 & 0 & 0 & 4 \\
\hline
\end{tabular}

Antimicrobial susceptibility patterns of the confirmed E. coli pathotypes

All pathogenic strains confirmed by PCR techniques were subjected to four carbapenems, and meropenem had the highest percentage resistance (70\%). The percentage resistance against the other antimicrobials follow the order: imipenem (64\%), doripenem (56\%) and ertapenem (44\%), and intermediate responses were considered as resistant.

\section{Molecular characterization of the relevant carbapenem resistance genes}

Of the $77 \mathrm{E}$. coli pathotypes, $70 \mathrm{E}$. coli strains exhibited resistance against the test carbapenems and were further screened for the relevant carbapenem-resistance genes (CRGs). Result showed 29 (41\%) were positive for CRGs, out of which 24 strains (34\%) harbored $b / a_{N D M-1}, 8$ strains (11\%) harbored bla $a_{K P C}$ and 2 strains (3\%) harbored bla $O X A-48-l i k e$. Table 2 represents the distribution of multiple CRGs harbored by the E. coli strains.

Table 2

Distribution of single and multiple carbapenem-resistance genes among $E$. coli strains that were screened.

\begin{tabular}{|c|c|c|c|c|c|c|c|c|c|}
\hline \multirow{2}{*}{$\begin{array}{l}\text { Patterns of } \\
\text { multiple } \\
\text { resistance } \\
\text { genes }\end{array}$} & \multirow[b]{2}{*}{$\begin{array}{l}\text { IbeA/NMEC } \\
(\%)\end{array}$} & \multicolumn{7}{|c|}{ Number of $E$. coli pathtypes } & \multirow[t]{2}{*}{ Tota } \\
\hline & & $\begin{array}{l}\text { Aafl/EAEC } \\
(\%)\end{array}$ & $\begin{array}{l}\text { daae/DAEC } \\
(\%)\end{array}$ & $\begin{array}{l}b f p / E P E C \\
(\%)\end{array}$ & $\begin{array}{l}\text { It/ETEC } \\
(\%)\end{array}$ & $\begin{array}{l}\text { stx1/STEC } \\
(\%)\end{array}$ & $\begin{array}{l}\text { Unidentified } \\
\text { E. coli } \\
\text { pathtypes } \\
(\%)\end{array}$ & Source & \\
\hline $\begin{array}{l}\text { bla }_{\text {NDM-1, }} \\
\text { bla }_{\mathrm{KPC}} \\
\text { bla }_{\mathrm{OXA}-48-\text { like }}\end{array}$ & 0 & 0 & 0 & 0 & 0 & 0 & 0 & $\begin{array}{l}\text { Hospital } \\
\text { effluent, } \\
\text { WWTP }\end{array}$ & 0 \\
\hline $\begin{array}{l}\text { bla }_{\text {NDM-1 }} \\
\text { bla }_{\text {KPC }}\end{array}$ & 2 & 0 & 0 & 0 & 1 & 0 & 1 & $\begin{array}{l}\text { Hospital } \\
\text { effluent, } \\
\text { WWTP }\end{array}$ & 4 \\
\hline $\begin{array}{l}\text { bla }_{\mathrm{KPC}} \\
\text { bla }_{\mathrm{OXA}-48-\text { like }}\end{array}$ & 0 & 0 & 0 & 0 & 0 & 0 & 0 & $\begin{array}{l}\text { Hospital } \\
\text { effluent, } \\
\text { WWTP }\end{array}$ & 0 \\
\hline $\begin{array}{l}\text { bla }_{\text {NDM-1, }} \\
\text { bla }_{\text {OXA-48-like }}\end{array}$ & 1 & 0 & 0 & 0 & 0 & 0 & 0 & $\begin{array}{l}\text { Hospital } \\
\text { effluent }\end{array}$ & 1 \\
\hline bla $_{\text {NDM-1 }}$ & 3 & 3 & 1 & 0 & 2 & 3 & 6 & $\begin{array}{l}\text { Hospital } \\
\text { effluent, } \\
\text { River, } \\
\text { Irrigation } \\
\text { water, } \\
\text { Vegetable }\end{array}$ & 18 \\
\hline bla $_{\text {KPC }}$ & 2 & 0 & 1 & 0 & 0 & 1 & 0 & $\begin{array}{l}\text { WWTP, } \\
\text { Soil }\end{array}$ & 4 \\
\hline bla $0 \times A-48-$ like & 0 & 0 & 0 & 0 & 0 & 1 & 0 & Vegetable & 1 \\
\hline
\end{tabular}

Prevalence of the antimicrobial resistance genes (ARGs) in the E. coli pathotypes 
After antibiotic susceptibility testing, all the E. coli strains that exhibited phenotypic resistance were further screened for the presence of carbapenem-resistance genes (CRGs). Results showed the isolates recovered from WWTPs final effluent (29\%) had the highest prevalence of CRGs. Supplementary Figures S3 and S4 represent the PCR products of the amplification of the relevant CRGs. Figure 1 shows the proportions of the confirmed E. coli strains harboring ARGs in the different environmental samples collected. Results showed only NMEC strains recovered from hospital effluent and WWTP final effluent harbored multiple CRGs.

\section{ERIC-PCR of amplified E. coli strains}

Analysis of the genetic diversity of the 31 collected E. coli strains was carried out by ERIC-PCR fingerprint method using ERIC-I and ERIC-2 primers. The fingerprints obtained from the ERIC typing of the 31 CREC strains showed a DNA banding profile consisting of amplified bands ranging from 1 to 13 having size $100 \mathrm{bp}$ to $5000 \mathrm{bp}$ (Fig. 2). The gel image banding patterns of pathogenic strains of $E$. coli were diverse in relation to the distribution of the polymorphic bands. The most frequent band size was $1500 \mathrm{bp}$, which was observed with 23 strains, and the least frequent band size was $100 \mathrm{bp}$, which was found in one strain.

\section{Dendrogram and clustering analysis}

GelJ uses implemented clustering algorithms to generate dendrograms with the similarity-matrices. The software offers different methods to construct dendrograms based on hierarchical clustering, automatically selecting unweighted pair group method with arithmetic mean (UPGMA) which is the most used method. The dendrogram analysis showed that there were a total of 7 unique clusters (CL) of ERIC (CL-1 to CL-7) within the 31 E. coli strains (Figs. 3). Only two clusters (CL-4 and CL-6) represented three different pathotypes while the three clusters (CL-1, CL-2 and CL-7) contained two different pathotypes varying from strains harboring virulence genes to unidentified pathotypes. The dendrogram image obtained from GelJ v.2.0 clustering analysis showed that the highest ERIC-genotype cluster of E. coli strains produced was observed in CL-6 (comprised 8 strains each), followed by CL-4 and CL-7 (composed of 4 strains respectively), followed by CL-1, CL-2 and CL-5 (composed of 3 strains respectively) and lastly CL-3 (composed of 2 strains). Different E. coli strains isolated from different sources in the ERIC-PCR profile (two different strains from CL-2 and three different strains from CL-4 and CL-6) were found in the same clusters and this is an indication of clonal similarities between them. Results obtained from the dendrograms showed that strains in the CL-5 were recovered from irrigation water and farm soil, while those in CL- 6 were recovered from three different sources which include river water, irrigation water and farm soil. Strains in CL-4 were also isolated from three different sources (hospital effluent, final effluent and farm soil). The similarity cut-off value of the different strains of $E$. coli detected was $95 \%$ for Fig. 3.

\section{Discussion}

The development of antimicrobial resistance genes (ARGs) in Enterobacteriaceae members has become a global health problem because antibiotic resistance (AR) leads to limitations in the treatment options thereby increasing the rate of morbidity and mortality [38]. Although carbapenem resistance (CR) among E. coli strains has been globally reported [39, 40,41], there is a dearth of information on Carbapenem-resistant Escherichia coli (CREC) isolated from different environmental niches in South Africa. In the Eastern Cape Province, this is the first study that evaluates the genetic diversity among CREC strains using Enterobacterial Repetitive Intergenic Consensus Polymerase Chain Reaction (ERIC-PCR) genotyping. The sources of contamination and AR patterns may generally be understood by using specific molecular marker to analyze the clonal similarities among bacterial isolates recovered from different environmental niches.

Among the total amount of presumptive $E$. coli isolates (238), the quantity of positively confirmed $E$. coli isolates (192/83\%) was unsurprisingly very high and this was similar to other studies by Blaak et al. [42] and Maamar et al. [43] with both reporting high incidence of $E$. coli isolates from farm environments. In another study by Araújo et al. [44], E. coli was isolated from irrigation water as well as vegetable samples and this is in line with our findings. This study provides an evidence of the occurrence of pathogenic microorganisms in the environment linking to other niches and our results show the occurrence of CREC in farm samples (Fig. 1).

The natural environment plays a major part in the emergence of AR pathogens as a result of the discharge of WWTP final effluents into receiving surface waters which may be used for domestic and irrigation purposes $[45,46]$. The reuse of wastewater in agricultural settings also contributes microbial flora to the natural environment [47], for instance during farm practices, there is high tendency of microbes being transferred to farm animals hence, some pathogens (such as bacteria, parasites, viruses) often emerge as zoonotic in origin. Previously established pathogens associated with raw farm produce (including fruits and vegetables) may re-emerge as more virulent pathogens (particularly $E$. coli) after the acquisition of new virulence factors, including AR determinants [48]. In this study, our findings show that at least 4 categories of diarrheagenic $E$. coli (DEC) are recognized, namely ETEC, EPEC, EAEC and STEC having a total of about $21 \%$ from $40 \%$ pathogenic E. coli strains that were recovered. Our results are in line with the results of Canizalez-Roman et al. [49] that reported the prevalence of some DEC strains isolated from food samples.

In this current study, meropenem had the highest percentage resistance (70\%), next to imipenem (64\%). Interestingly, our findings are in line with a report by Kagambega et al. [50] conducted in Burkina Faso and this is an evidence of the detection of multidrug resistant (MDR) E. coli strains in sub-Sahara Africa. Our results show that at least one out of the 6 detected E. coli pathotypes exhibited phenotypic resistance against one of the 4 test carbapenems (doripenem, imipenem, meropenem, ertapenem) while ertapenem had the highest antimicrobial activity as also reported in a study by Kuzucu et al. [51]. Although, little is known about the spread and clinical relevance of carbapenemase-producing genes (CRGs) in Africa, studies 
of Manenzhe et al. [52] and Brink et al. [53] provided some reports that investigated various ARGs. In another study by Cakar et al. [54], it was also reported that CRGs were abundant in bacterial isolates of Enterobacteriaceae family. Moquet et al. [55] and Baroud et al. [56] both investigated the

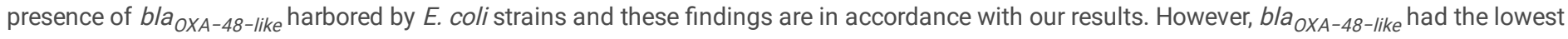
percentage occurrence among the other selected CRGs that were screened for in our present study. Another study by Fischer et al. [57] revealed that E. coli harbored $b / a_{V I M-1}$ gene in their report, although this gene was not screened for in this present study.

In our study, farm samples (comprising soil, vegetables and irrigation water) had the lowest percentage occurrence (7\%) of CRGs among the sample types which may be due to washing after harvesting, however our findings suggest a public health risk and probability of illness if raw vegetables are consumed without washing properly. Moreover, irrigation water had the lowest prevalence (4\%) which may be due to the reduction in numbers as a result of environmental or climatic factors that can affect the survival of the microorganisms in the aquatic environments. Hospital effluents (32\%) and WWTP final effluents (29\%) are evidently proven hotspots of pathogenic microorganisms that may harbour ARGs. Furthermore, our study corroborates with one health strategies to address AR, through improving awareness and understanding of antimicrobial resistance (AMR) by effective communication, education as well as training. To determine the relative implications of AMR emergence and spread in food-animal production, there is a significant challenge due to the interconnectedness as well as interdependence of epidemiological pathways between humans, animals and the environment [58]. In our present study, hospital wastewater isolates cutting across the various $E$. coli pathotypes harboured all three carbapenem-resistance genes but bla $\mathrm{NDM}_{-1}$ occurred the most. Among the farm samples, only STEC strains harboured CRGs.

Some selected E. coli strains were investigated genetically with the use of ERIC-PCR. Osińska et al. [59] reported ERIC-PCR genomic fingerprinting technique as a vital tool for evaluating genetic relationships between bacterial strains isolated from environmental niches and some other studies reported ERIC-PCR genotypic diversity of multidrug resistant (MDR) bacterial strains isolated from different sources [60, 61], However, in this study we analyzed selected E. coli strains comprising some CREC with the use of ERIC- fingerprinting in order to evaluate the links that exist between strains isolated from different sources. ERIC-PCR has been demonstrated to be an effective method in determining the genetic diversity or relatedness among bacterial species by grouping clusters according to band sizes [62]. Some strains showed equal clusters but were isolated from different sources and this indicates clonal similarities between these strains which may be as a result of a possible link between final effluent and receiving water sheds. In light of the various inter- and intra-genotypic background of $E$. coli pathotypes, it is of concern to comprehend if there is a connection between the ERIC-genotype and the existence of pathogenic E. colistrains in poorly treated WWTP final effluent which is being discharged into receiving surface waters.

In our study, 7 clusters of ERIC-PCR were generated from 31 pathogenic E. coli strains (Figs. 3) at 95 per cent similarity cut-off value and exhibited genetic heterogeneity, but Jonas et al. [63] reported isolates with similarities above $70-80 \%$ which were eventually assigned to the same genotypes. Another study by Pusparini et al. [64] reported several unique clusters of ERIC in E. coli strains isolated from ice cube production sites which showed genetic diversity with 50 per cent cut-off value which is in contrary to the similarity cut-off value generated in this present study. On the basis of ERICPCR fingerprint, some of the isolates included in our study were genetically diverse. This is the most expected outcome as the pathogenic strains were isolated after being randomly collected from different environmental sources during sample collection which demonstrates that, the transmission might have occurred from clones of different origins. These findings corroborated with other studies [65, 66, 67]. Some other studies that used ERIC-PCR in E. coli isolated from other sources include Zhang et al. [68] who reported genetic diversity analysis of E. coli serotypes isolated from retail foods in China and Oltramar et al. [69] who reported genetic heterogeneity of $E$. coli isolated from pasteurized milk in Brazil. In our present study, river water samples were also collected and this is corroborated by a study by Lyautey et al. [70] who reported distribution and diversity of $E$. coli in river water samples collected in Canada.

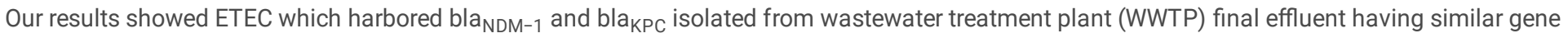
clusters as strains from river water samples. This may be as a result of discharge of final effluent into the river because both samples were collected from the same study area. A study by Shaikh et al. [71] reported genetic diversity in E. coli and another member of Enterobacteriaceae (Klebsiella pneumonia) which were both isolated from clinical samples; however, in our present study, clinical samples were not collected. Our present study showed varied genetic diversity between three strains of neonatal meningitis $E$. coli (NMEC) isolated from WWTP final effluent and river water samples and this is in line with a study by Levert et al. [72] who reported genetic diversity of extraintestinal pathogenic strains of $E$. coli. In this study, STEC had the highest number of ERIC-PCR genotypes and our findings are in contrary with the report by Moredo et al. [73] where ETEC reportedly had the highest EPIC-PCR genotypes. Studies by Yasir et al. [74] and Sun et al. [75] reported the genetic diversities in multidrug resistant ESBLproducing $E$. coli although, our study did not screen for ESBL in the E. coli strains nevertheless provides an opportunity for further analysis. EPEC strains were predominantly isolated from river water samples and our study corroborates with another report by Khare et al. [76]. Our current study used ERIC-PCR to identify the various sources and this is supported by lbekwe et al. [77] who reported $E$. coli isolated from swine wastewater samples in the United States.

This is the first study reporting the genetic diversity of carbapenem-resistant $E$. coli strains isolated from different environmental sources in the Eastern Cape Province, with other studies by Montso et al. [78] and Chukwu et al. [79] reporting on the genotypic diversity of E. coli isolates recovered from farms and water samples respectively both in the North West Province.

\section{Conclusion}


The detection of CREC in different environmental niches in the Eastern Cape Province, South Africa provides an evidence of high infection risk and this poses a public health concern. The occurrence of ARGs in isolates recovered from vegetables may be linked with the possibility of transmission of these genes as a result of the various farm practices and probably wastewater reuse for irrigation purposes and this is a public health worry. We suggest more surveillance studies to be carried out to screen for more ARGs harbored by various ARB especially the Enterobacteriaceaefamily and development of more effective strategies to control and manage the use of antimicrobial agents. More studies analyzing the genotypic diversity should be encouraged in the Eastern Cape Province and its surroundings. The results obtained by ERIC-PCR approaches reinforce the conclusion of the present study. Overall, the study concludes that ERIC-PCR had good differentiation power for molecular typing and genetic diversity of $E$. coli strains isolated from selected environmental niches and ERIC-PCR proved to be swift and cost-effective molecular-genomic tool for members of the Enterobacteriaceae group.

\section{Description Of Supplementary Materials}

The following are available as supplementary materials, Supplementary Figures: Figure S1. PCR products of the amplification of uidA gene (E. coli); Figure S2. PCR products of the amplification of $i b e A$ gene (NMEC); Figure S3. PCR products of the amplification of $b l a_{N D M-1}$ gene; Figure S4. PCR products of the amplification of bla ${ }_{K P C}$ gene. Supplementary Table S1. List of primers for the PCR confirmation of E. coli, VG, ERIC-PCR and their corresponding amplicon sizes and PCR conditions.

\section{Declarations}

\section{Acknowledgements}

We would like to thank the "South African Medical Research Council (SAMRC)" and "University of Fort Hare" for their kind cooperation. This study was supported financially by SAMRC.

\section{Availability of data and materials}

All data generated or analyzed during this study are included in this published article.

\section{Authors' Contribution}

K.E.E performed laboratory works, analyzed the data and drafted the paper. A.I.O designed the study, interpreted the data and revised the manuscript. All authors read and approved the final manuscript.

\section{Ethics approval and consent to participate}

Not applicable.

\section{Consent for publication}

Not applicable.

\section{Competing interests}

The authors declare that they have no competing interests.

\section{References}

1. Flemming HC, Wingender J, Szewzyk U, Steinberg P, Rice SA, Kjelleberg S. Biofilms: an emergent form of bacterial life. Nat Rev Microbiol. 2016;14(9):563.

2. Singh AK, Das S, Singh S, Gajamer VR, Pradhan N, Lepcha YD, et al. Prevalence of antibiotic resistance in commensal Escherichia coli among the children in rural hill communities of Northeast India. PloS one. 2018;13(6):0199179.

3. Paruch AM, Mæhlum T. Specific features of Escherichia coli that distinguish it from coliform and thermotolerant coliform bacteria and define it as the most accurate indicator of faecal contamination in the environment. Ecol Ind. 2012;23:140-2.

4. Brandal LT, Lindstedt BA, Aas L, Stavnes TL, Lassen J, Kapperud G. Octaplex PCR and fluorescence-based capillary electrophoresis for identification of human diarrheagenic Escherichia coli and Shigella spp. J Microbiol Methods. 2007;68(2):331-41. 
5. Jafari A, Aslani MM, Bouzari S. Escherichia coli: a brief review of diarrheagenic pathotypes and their role in diarrheal diseases in Iran. Iranian journal of microbiology. 2012;4(3):102.

6. Ebomah KE, Adefisoye MA, Okoh Al. Pathogenic Escherichia coli Strains Recovered from Selected Aquatic Resources in the Eastern Cape, South Africa, and Its Significance to Public Health. Int J Environ Res Public Health. 2018;15(7):1506.

7. Rodríguez-Baño J, Gutiérrez-Gutiérrez B, Machuca I, Pascual A. Treatment of infections caused by extended-spectrum-beta-lactamase, AmpC,and carbapenemase-producing Enterobacteriaceae. Clin Microbiol Rev. 2018;31(2):00079-17.

8. Cassini A, Högberg LD, Plachouras D, Quattrocchi A, Hoxha A, Simonsen GS, et al. Attributable deaths and disability-adjusted life-years caused by infections with antibiotic-resistant bacteria in the EU and the European Economic Area in 2015: a population-level modelling analysis. Lancet Infect Dis. 2019;19(1):56-66.

9. Goodman KE, Simner PJ, Tamma PD, Milstone AM. Infection control implications of heterogeneous resistance mechanisms in carbapenemresistant Enterobacteriaceae (CRE). Expert Review of Anti-infective Therapy. 2016;14(1):95-108.

10. Munita JM, Arias CA. Mechanisms of antibiotic resistance. Microbiology Spectrum. 2016;4:481-511.

11. Mehrad B, Clark NM, Zhanel GG, Lynch JP III. Antimicrobial resistance in hospital-acquired Gram-negative bacterial infections. Chest. 2015;147(5):1413-21.

12. Zilberberg MD, Nathanson BH, Sulham K, Fan W, Shorr AF. Carbapenem resistance, inappropriate empiric treatment and outcomes among patients hospitalized with Enterobacteriaceae urinary tract infection, pneumonia and sepsis. BMC Infect Dis. 2017;17(1):279.

13. Piazza A, Comandatore F, Romeri F, Pagani C, Floriano AM, Ridolfo A, et al. First report of an ST410 OXA-181 and CTX-M-15 coproducing Escherichia coli clone in Italy: a whole-genome sequence characterization. Microbial Drug Resistance. 2018;24(8):1207-9.

14. Sanderson H, Brown RS, Hania P, McAllister TA, Majury A, Liss SN. Antimicrobial Resistant Genes and Organisms as Environmental Contaminants of Emerging Concern: Addressing Global Public Health Risks. In: Management of Emerging Public Health Issues and Risks. London: Academic Press Elsevier; 2019. pp. 147-87.

15. Al-Jassim N, Mantilla-Calderon D, Wang T, Hong PY. Inactivation and gene expression of a virulent wastewater Escherichia coli strain and the nonvirulent commensal Escherichia coli DSM1103 strain upon solar irradiation. Environ Sci Technol. 2017;51(7):3649-59.

16. Vikesland P, Garner E, Gupta S, Kang S, Maile-Moskowitz A, Zhu N. Differential Drivers of Antimicrobial Resistance across the World. Acc Chem Res. 2019;52(4):916-24.

17. Hentati O, Chaker S, Wali A, Ayoub T, Ksibi M. Effects of long-term irrigation with treated wastewater on soil quality, soil-borne pathogens, and living organisms: case study of the vicinity of El Hajeb (Tunisia). Environ Monit Assess. 2014;186(5):2671-83.

18. Becerra-Castro C, Lopes AR, Vaz-Moreira I, Silva EF, Manaia CM, Nunes OC. Wastewater reuse in irrigation: A microbiological perspective on implications in soil fertility and human and environmental health. Environ Int. 2015;75:117-35.

19. Qureshi AS, Hussain MI, Ismail S, Khan QM. Evaluating heavy metal accumulation and potential health risks in vegetables irrigated with treated wastewater. Chemosphere. 2016;163:54-61.

20. Cerqueira F, Matamoros V, Bayona JM, Berendonk TU, Elsinga G, Hornstra LM, et al. Antibiotic resistance gene distribution in agricultural fields and crops. A soil-to-food analysis. Environmental research. 2019;177:108608.

21. Arshad M, Zafar R. Antibiotics. AMRs, and ARGs: fate in the environment. Antibiotics Antimicrobial Resistance Genes in the Environment. 2020;1:138-54.

22. Finley RL, Collignon P, Larsson DJ, McEwen SA, Li XZ, Gaze WH, et al. The scourge of antibiotic resistance: the important role of the environment. Clinical infectious diseases. 2013;57(5):704-10.

23. Sabat AJ, Budimir A, Nashev D, Sá-Leão R, Van Dijl JM, Laurent F, et al. ESCMID Study Group of Epidemiological Markers (ESGEM). Overview of molecular typing methods for outbreak detection and epidemiological surveillance. Eurosurveillance. 2013;18(4):20380.

24. Ranjbar R, Tabatabaee A, Behzadi P, Kheiri R. Enterobacterial repetitive intergenic consensus polymerase chain reaction (ERIC-PCR) genotyping of Escherichia coli strains isolated from different animal stool specimens. Iranian journal of pathology. 2017;12(1):25.

25. Ardakani MA, Ranjbar R. Molecular typing of uropathogenic E. coli strains by the ERIC-PCR method. Electronic physician. 2016;8(4):2291.

26. Ranjbar R, Karami A, Farshad S, Giammanco GM, Mammina C. Typing methods used in the molecular epidemiology of microbial pathogens: a how-to guide. The new microbiologica. 2014;37(1):1-15.

27. Pereira F, Carneiro J, Amorim A. Identification of species with DNA-based technology: current progress and challenges. Recent patents on DNA gene sequences. 2008;2(3):187-200.

28. Zhang Y, Liao YT, Salvador A, Sun X, Wu VC. Prediction, diversity, and genomic analysis of temperate phages induced from Shiga toxinproducing Escherichia coli strains. Frontiers in microbiology. 2020;10:3093.

29. Ebomah KE, Okoh Al. An African perspective on the prevalence, fate and effects of carbapenem resistance genes in hospital effluents and wastewater treatment plant (WWTP) final effluents: A critical review. Heliyon. 2020;6(5):03899.

30. Jacobs NJ, Zeigler WL, Reed FC, Stukel TA, Rice EW. Comparison of membrane filter, multiple-fermentation-tube, and presence-absence techniques for detecting total coliforms in small community water systems. Appl Environ Microbiol. 1986;51(5):1007-12. 
31. Du Plessis KR, Botha A, Joubert L, Bester R, Conradie WJ, Wolfaardt GM. Response of the microbial community to copper oxychloride in acidic sandy loam soil. J Appl Microbiol. 2005;98(4):901-9.

32. Da Silva N, Taniwaki MH, Junqueira VC, Silveira N, Okazaki MM, Gomes RAR. Microbiological Examination Methods of Food and Water: A Laboratory Manual. CRC Press; 2018.

33. Jackson DP, Lewis FA, Taylor GR, Boylston AW, Quirke P. Tissue extraction of DNA and RNA and analysis by the polymerase chain reaction. J Clin Pathol. 1990;43(6):499-504.

34. Ahmed W, Tucker J, Bettelheim KA, Neller R, Katouli M. Detection of virulence genes in Escherichia coli of an existing metabolic fingerprint database to predict the sources of pathogenic E. coli in surface waters. Water Res. 2007;41(16):3785-91.

35. Performance Standards for Antimicrobial Susceptibility Testing. 27th ed. CLSI supplement M100. Clinical and Laboratory Standards Institute, Wayne, PA, USA; 2017.

36. Salloum T, Arabaghian H, Alousi S, Abboud E, Tokajian S. 2017. Genome sequencing and comparative analysis of an NDM-1-producing Klebsiella pneumoniaeST15 isolated from a refugee patient. Pathogens and global health. 2017;111(4):166-175.

37. Heras J, Domínguez C, Mata E, Pascual V, Lozano C, Torres C, et al. GelJ-a tool for analyzing DNA fingerprint gel images. BMC Bioinform. 2015;16(1):1-8.

38. Mairi A, Pantel A, Sotto A, Lavigne JP, Touati A. OXA-48-like carbapenemases producing Enterobacteriaceae in different niches. Eur J Clin Microbiol Infect Dis. 2018;37(4):587-604.

39. Said LB, Jouini A, Alonso CA, Klibi N, Dziri R, Boudabous A, et al. Characteristics of extended-spectrum $\beta$-lactamase (ESBL)-and pAmpC betalactamase-producing Enterobacteriaceae of water samples in Tunisia. Science of The Total Environment. 2016;550(1):1103-9.

40. ur Rahman S, Ahmad S, Khan I, Pakistan P. Incidence of ESBL-Producing-Escherichia coli in Poultry Farm Environment and Retail Poultry Meat. Pak Vet J. 2018;39(1):116-20.

41. Osińska A, Korzeniewska E, Harnisz M, Niestępski S. Quantitative Occurrence of Antibiotic Resistance Genes among Bacterial Populations from Wastewater Treatment Plants Using Activated Sludge. Applied Sciences. 2019;9(3):387.

42. Blaak $H$, van Hoek AH, Hamidjaja RA, van der Plaats RQ, Kerkhof-de Heer L, de Roda Husman AM, et al. Distribution, numbers, and diversity of ESBL-producing E. coli in the poultry farm environment. PloS One. 2015;10(8):0135402.

43. Maamar E, Hammami S, Alonso CA, Dakhli N, Abbassi MS, Ferjani S, et al. High prevalence of extended-spectrum and plasmidic AmpC betalactamase-producing Escherichia coli from poultry in Tunisia. Int J Food Microbiol. 2016;231(1):69-75.

44. Araújo S, Silva IA, Tacão M, Patinha C, Alves A, Henriques I. Characterization of antibiotic resistant and pathogenic Escherichia coli in irrigation water and vegetables in household farms. Int J Food Microbiol. 2017;257(1):192-200.

45. Huijbers PM, Blaak H, de Jong MC, Graat EA, Vandenbroucke-Grauls CM. Roda Husman, Role of the environment in the transmission of antimicrobial resistance to humans: a review. Environ Sci Technol. 2015;49(20):11993-2004. A.M. de.

46. Mhamdi F, Khouni I, Ghrabi A. Diagnosis and characteristics of water quality along the Wadi El Bey river (Tunisia). Coagulation/flocculation essays of textile effluents discharged into the Wadi. Desalination Water Treatment. 2016;57(46):22166-88.

47. Adegoke AA, Amoah ID, Stenström TA, Verbyla ME, Mihelcic JR. Epidemiological Evidence and Health Risks Associated with Agricultural Reuse of Partially Treated and Untreated Wastewater: A Review. Frontiers in Public Health. 2018;6(1):337.

48. Smith JL, Fratamico PM. Emerging and Re-Emerging Foodborne Pathogens. Foodborne Pathogens Disease. 2018;15(12):737-57.

49. Canizalez-Roman A, Gonzalez-Nuñez E, Vidal JE, Flores-Villaseñor H, León-Sicairos N. Prevalence and antibiotic resistance profiles of diarrheagenic Escherichia coli strains isolated from food items in northwestern Mexico. Int J Food Microbiol. 2013;164(1):36-45.

50. Kagambega A, Martikainen O, Siitonen A, Traore AS, Barro N, Haukka K. Prevalence of diarrheagenic Escherichia coli virulence genes in the feces of slaughtered cattle, chickens, and pigs in Burkina Faso. MicrobiologyOpen. 2012;1(3):276-84.

51. Kuzucu C, Yetkin F, Görgeç S, Ersoy Y. Investigation of the susceptibilities of extended-spectrum beta-lactamase-producing Escherichia coli and Klebsiella spp. strains to ertapenem and other carbapenems. Mikrobiyoloji Bulteni. 2011;45(1):28-35.

52. Manenzhe RI, Zar HJ, Nicol MP, Kaba M. The spread of carbapenemase-producing bacteria in Africa: a systematic review. Journal of antimicrobial chemotherapy. 2015;70(1):23-40.

53. Brink A, Coetzee J, Clay C, Corcoran C, Van Greune J, Deetlefs JD, et al. The spread of carbapenem-resistant Enterobacteriaceae in South Africa: Risk factors for acquisition and prevention. SAMJ: South African Medical Journal. 2012;102(7):599-601.

54. Cakar A, Akyön Y, Gür D, Karatuna O, Öğünç D, Özhak BB, et al. Investigation of carbapenemases in carbapenem-resistant Escherichia coli and Klebsiella pneumoniae strains isolated in 2014 in Turkey. Mikrobiyoloji Bulteni. 2016;50(1):21-33.

55. Moquet O, Bouchiat C, Kinana A, Seck A, Arouna O, Bercion R, et al. Class D OXA-48 carbapenemase in multidrug-resistant enterobacteria, Senegal. Emerg Infect Dis. 2011;17(1):143.

56. Baroud A, Dandache I, Araj GF, Wakim R, Kanj S, Kanafani Z, et al. Underlying mechanisms of carbapenem resistance in extended-spectrum $\beta$ lactamase-producing Klebsiella pneumoniae and Escherichia coli isolates at a tertiary care center in Lebanon: role of OXA-48 and NDM-1 carbapenemases. International Journal of Antimicrobial Agents. 2013;41(1):75-79. 
57. Fischer J, Rodríguez I, Schmoger S, Friese A, Roesler U, Helmuth R, et al. Escherichia coli producing VIM-1 carbapenemase isolated on a pig farm. J Antimicrob Chemother. 2012;67(7):1793-5.

58. Wall BA, Mateus ALP, Marshall L, Pfeiffer DU, Lubroth J, Ormel HJ, et al. Drivers, dynamics and epidemiology of antimicrobial resistance in animal production. Food and Agriculture Organization of the United Nations; 2016.

59. Osińska A, Korzeniewska E, Harnisz M, Niestępski S. The prevalence and characterization of antibiotic-resistant and virulent Escherichia coli strains in the municipal wastewater system and their environmental fate. Sci Total Environ. 2017;577(1):367-75.

60. Ateba CN, Mbewe M. Determination of the genetic similarities of fingerprints from Escherichia coli $0157: H 7$ isolated from different sources in the North West Province, South Africa using ISR, BOXAIR and REP-PCR analysis. Microbiological research. 2013;168(7):438-46.

61. Ying C, Li Y, Wang Y, Zheng B, Yang C. Investigation of the molecular epidemiology of Acinetobacter baumannii isolated from patients and environmental contamination. J Antibiot. 2015;68(9):562-7.

62. Bastas KK, Kannan VR. 4 Controlling Strategies (Diagnosis/Quarantine/Eradication) of Plant Pathogenic Bacteria. Sustainable Approaches to Controlling Plant Pathogenic Bacteria; 2015. p. 81.

63. Jonas D, Spitzmüller B, Weist K, Rüden H, Daschner FD. Comparison of PCR-based methods for typing Escherichia coli. Clinical microbiology infection. 2003;9(8):823-31.

64. Pusparini N, Waturangi DE, Usia T, Nikastri E. Genetic diversity of Escherichia coli isolated from ice cube production sites. BMC Res Notes. 2018;11(1):1-8.

65. Parajuli NP, Maharjan P, Parajuli H, Joshi G, Paudel D, Sayami S, et al. High rates of multidrug resistance among uropathogenic Escherichia coli in children and analyses of ESBL producers from Nepal. Antimicrobial Resistance Infection Control. 2017;6(1):9.

66. Koczura R, Mokracka J, Jabłońska L, Gozdecka E, Kubek M, Kaznowski A. Antimicrobial resistance of integron-harboring Escherichia coli isolates from clinical samples, wastewater treatment plant and river water. Sci Total Environ. 2012;414(1):680-5.

67. Al-Kandari F, Woodward MJ. Genotypic and phenotypic diversity differences of presumptive commensal and avian pathogenic E. coli. British poultry science. 2019;60(1):79-86.

68. Zhang S, Zhu X, Wu Q, Zhang J, Xu X, Li H. Prevalence and characterization of Escherichia coli 0157 and 0157 : H7 in retail fresh raw meat in South China. Annals of microbiology. 2015;65(4):1993-9.

69. Oltramari K, Cardoso RF, Patussi EV, Santos ACB, Mikcha JMG. Genetic heterogeneity of Escherichia coli isolated from pasteurized milk in State of Paraná, Brazil. Brazilian Journal of Pharmaceutical Sciences. 2014;50(2):337-43.

70. Lyautey E, Lu Z, Lapen DR, Wilkes G, Scott A, Berkers T, et al. Distribution and diversity of Escherichia coli populations in the South Nation River drainage basin, eastern Ontario, Canada. Appl Environ Microbiol. 2010;76(5):1486-96.

71. Shaikh S, Rizvi SMD, Anis R, Shakil S. Prevalence of CTX-M resistance marker and integrons among Escherichia coli and Klebsiella pneumoniae isolates of clinical origin. Lett Appl Microbiol. 2016;62(5):419-27.

72. Levert M, Zamfir O, Clermont O, Bouvet O, Lespinats S, Hipeaux MC, et al. Molecular and evolutionary bases of within-patient genotypic and phenotypic diversity in Escherichia coli extraintestinal infections. PLoS pathogens. 2010;6(9):1001125.

73. Moredo FA, Pineyro PE, Márquez GC, Sanz M, Colello R, Etcheverria A, et al. Enterotoxigenic Escherichia coli subclinical infection in pigs: bacteriological and genotypic characterization and antimicrobial resistance profiles. Foodborne Pathog Dis. 2015;12(8):704-11.

74. Yasir M, Ajlan AM, Shakil S, Jiman-Fatani AA, Almasaudi SB, Farman M, et al. Molecular characterization, antimicrobial resistance and clinicobioinformatics approaches to address the problem of extended-spectrum $\beta$-lactamase-producing Escherichia coli in western Saudi Arabia. Scientific reports. 2018;8(1):1-11.

75. Sun J, Zheng F, Wang F, Wu K, Wang Q, Chen Q, et al. Class 1 integrons in urinary isolates of extended-spectrum $\beta$-lactamase-producing Escherichia coli and Klebsiella pneumoniae in Southern China during the past five years. Microbial Drug Resistance. 2013;19(4):289-94.

76. Khare N, Kaushik M, Kumar S, Gulati P. Evaluation of genetic diversity among aquatic and fecal isolates of Escherichia coli using multilocus variable number of tandem repeat analysis. 3 Biotech. 2020;10(2):63.

77. Ibekwe AM, Murinda SE, DebRoy C, Reddy GB. Potential pathogens, antimicrobial patterns and genotypic diversity of Escherichia coli isolates in constructed wetlands treating swine wastewater. FEMS microbiology ecology. 2016;92(2).

78. Montso KP, Dlamini SB, Kumar A, Ateba CN. Antimicrobial Resistance Factors of Extended-Spectrum Beta-Lactamases Producing Escherichia coli and Klebsiella pneumoniae Isolated from Cattle Farms and Raw Beef in North-West Province, South Africa. BioMed Research International; 2019.

79. Chukwu MO, Abia ALK, Ubomba-Jaswa E, Obi LC, Dewar JB. Antibiotic resistance profile and clonality of E. coli isolated from water and paediatric stool samples in the north-west, province South Africa. J Pure Appl Microbiol. 2019;13:517-30.

\section{Figures}




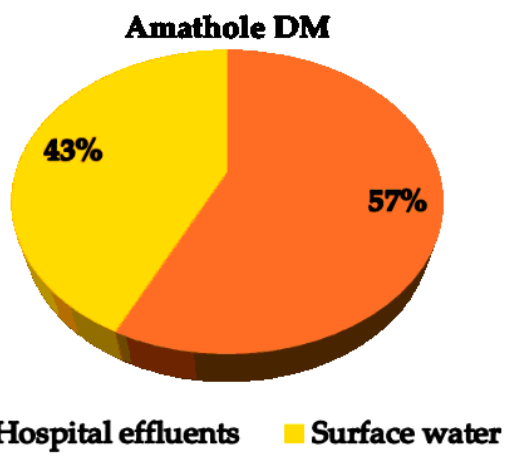

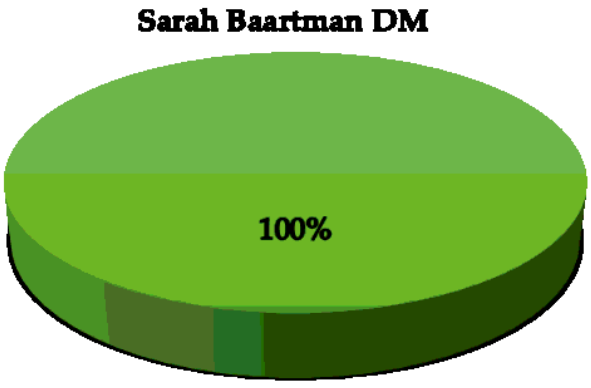

(b)

(a)

\section{$\square$ Hospital effluents $\quad$ Surface water}

\section{Chris Hani DM cfu/ml}

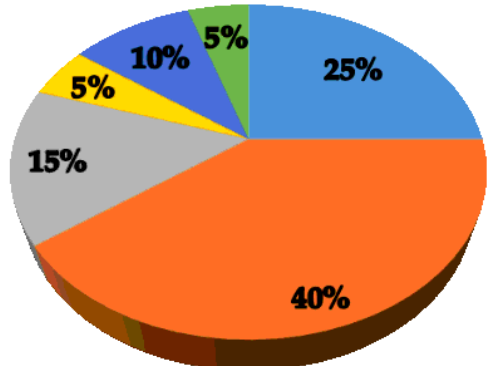

Hospital effluents

(c)

Soil
Final effluents

Irrigation water

Vegetables

\section{Figure 1}

The proportions of occurrence of E. coli strains with ARGs recovered from three District Municipalities in the Eastern Cape Province, South Africa. The following is the order of the percentage occurrence of carbapenem-resistance genes in the different sample types; (a) hospital effluents (57\%) and surface water (43\%), (b) vegetables (100\%), (c) final effluents (40\%), hospital effluents (25\%), surface water (15\%), soil (10\%), irrigation water (5\%) and vegetables (5\%).

$\begin{array}{llllllllllllll}M & 1 & 2 & 3 & 4 & 5 & 6 & 7 & 8 & 9 & 10 & 11 & 12 & 13\end{array}$

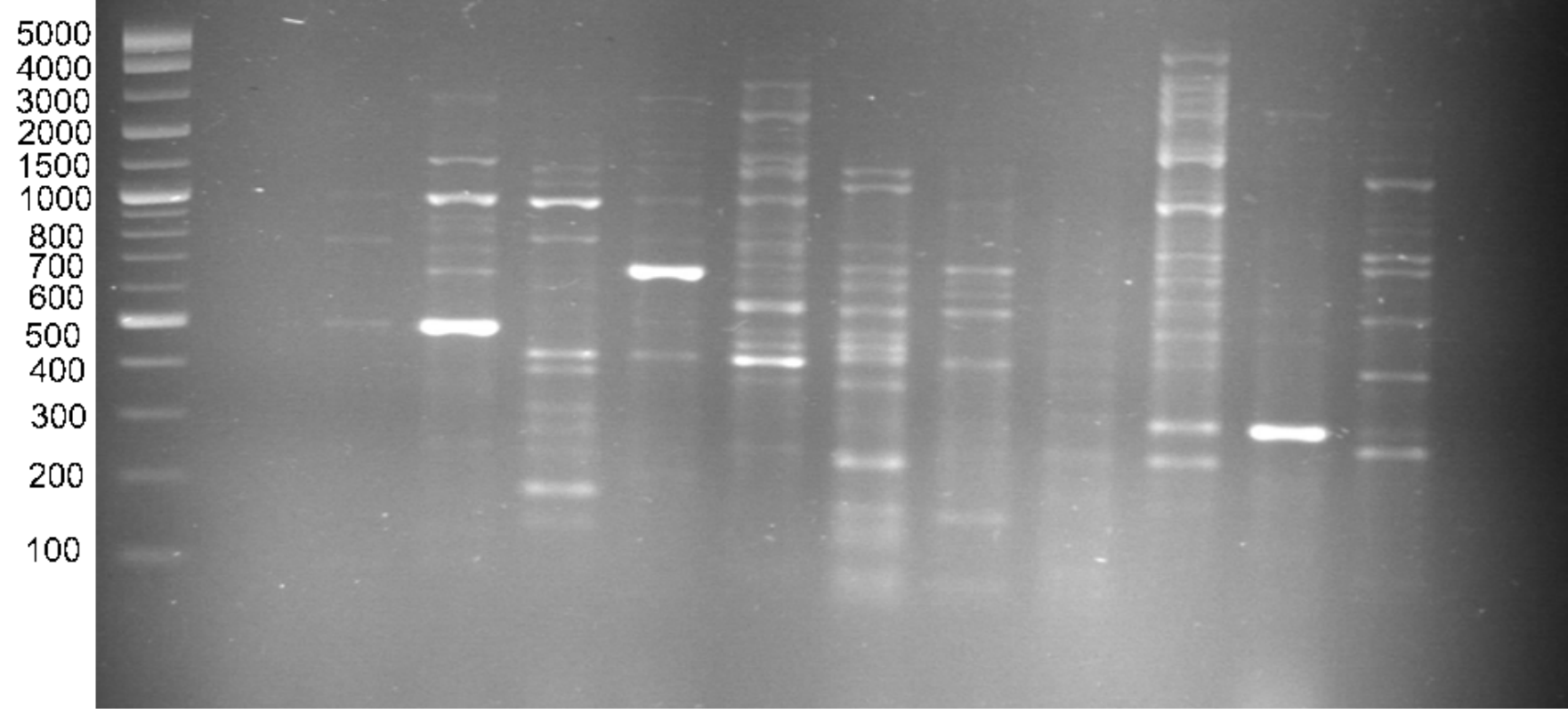

\section{Figure 2}

The Electrophoresis result by the Enterobacterial Repetitive Intergenic Consensus Polymerase Chain Reaction system 


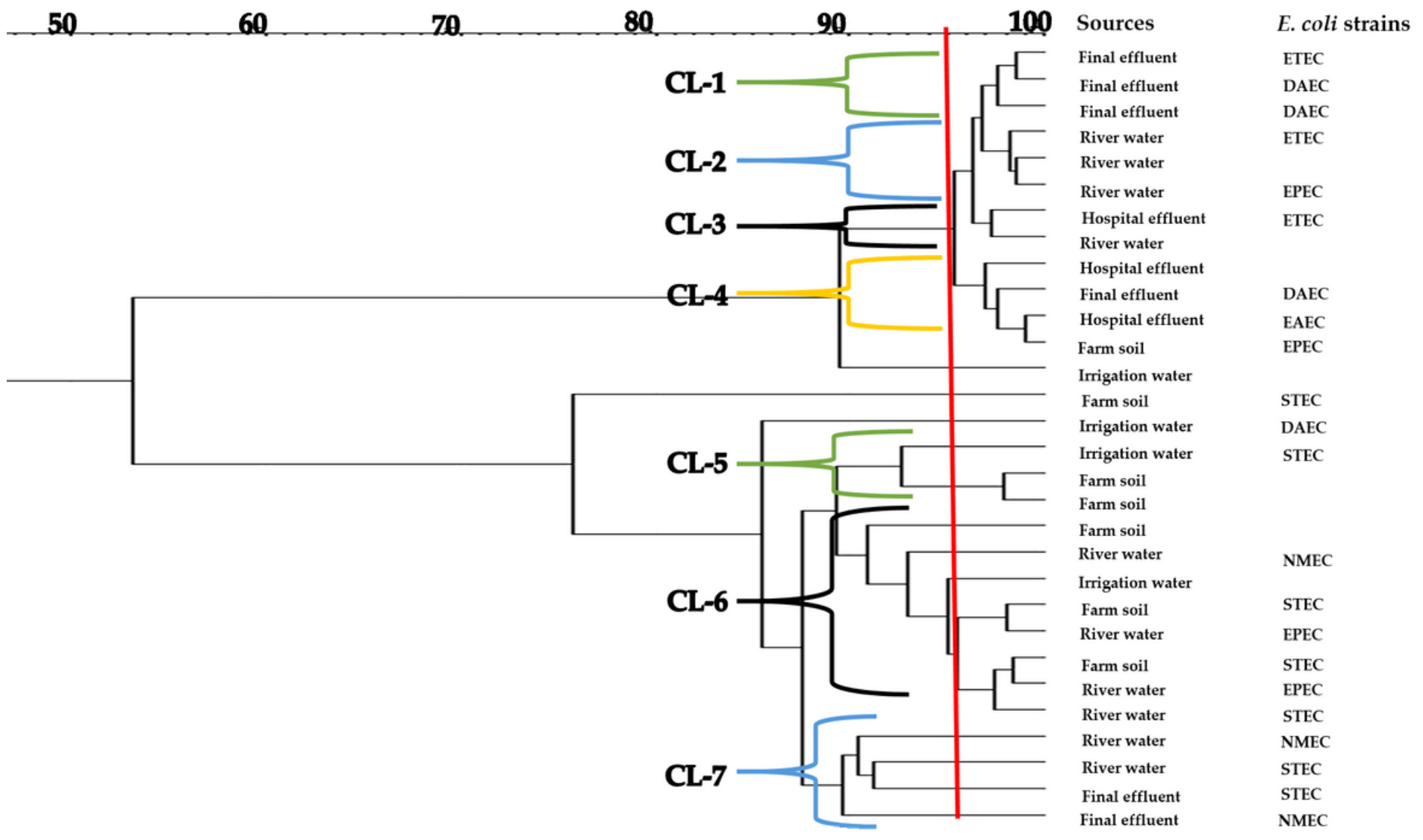

Figure 3

Dendrogram of 31 E. coli strains fingerprint by cluster analysis based on ERIC-PCR (CL = Cluster; Scale unit = percentage similarity index; Red-line = cut-off value; strain number missing = unidentified pathotypes).

\section{Supplementary Files}

This is a list of supplementary files associated with this preprint. Click to download.

- SupplementarymaterialsEbomahOkoh2020ERICPCR.docx 